\title{
Research on construction of multi-mode practice teaching system of mechatronic major
}

\author{
Ou Xie ${ }^{1, a}$, Guangxun wang ${ }^{1, b}$ and Bangfu Wang ${ }^{1, c}$ \\ ${ }^{1}$ School of Mechanical Engineering, Suzhou University of Science and Technology, \\ SuZhou 215009, china \\ ahnxieou@126.com, bguangxun_77@163.com, 'bfwang@mail.usts.edu.cn
}

Keywords: Mechatronic major; Multi-mode; Practice teaching; System

Abstract. Mechatronic is a major in project utility strongly, which determines the important role of practice teaching in college talent training. The changes of the current social demand for mechatronic talent are analyzed. The construction method and quality control system of multi-mode practice teaching system are elaborated. It provides guarantee for the cultivation of high quality and inter-disciplinary talent.

\section{Introduction}

Practice teaching is the basic link of mechatronic talent training, which plays a very important role in training students' practical ability and innovative ability to carry out quality education [1]. With the development of society and engineering and the change of educational demand, practice teaching needs continuously adapt to the development of the times, rethink its connotation and reform its system.

\section{The requirement of social development for mechatronic talents}

Mechatronic major is a multi-disciplinary cross integration, which include mechanical, electronic, optical, control, computer, information and so on. Its development and progress will promote the upgrading and adjustment of related technology industries. As industrial 4.0 is put forward, the higher requirements in training of mechatronic talents are presented. The past single talent training mode of heavy theory light practice will not be able to adapt the development of social industry. The industrial with the characteristics of internet, data, integration, innovation and transformation that proposed by Industry 4[2]require the mechatronic talents should have the following capabilities:

(1) Professional design ability. A qualified mechatronic talent must grasp rich professional knowledge, which can be engaged in design and development of related mechanical and electrical products or engineering projects.

(2) Innovative development ability. Market demand changes rapidly, only innovation can occupy the market in the fierce competition. As a mechatronic talent, you must have the ability to innovate and create, so as to driven the product industry upgrade.

(3) Teamwork ability. In modern time, the demand for knowledge and technology has not been able to rely on personal ability. Only team work can complete the big projects and achieve the effect of_one plus one big than two. Therefore, the mechatronic talent must have the ability of team work and coordination.

(4) Social communication ability. In the information and network age, people are no longer isolated individuals. No matter what kind of work you are engaged in, you must keep in touch with the society to achieve the goal. As a mechatronic talent, you must have the social communication ability to adapt to the economic development under the new situation.

\section{Reanalysis of the connotation of practice teaching}

Currently, weaken and ignore of practice teaching is mainly caused by some misunderstanding on the connotation of practice teaching[3]. These misunderstanding are mainly represented as follows: 
(1) Anaclisis. Practice teaching is regarded as a link or supplement of theoretical teaching to explain and vivificate the theoretical knowledge in classroom teaching, and acts as the service role of theoretical teaching.

(2) Narrowness. In practical work, practice teaching is mostly understood and used on the level in practice, training and experiment. The training aim and function of practice teaching only or basically positioned on the training of students' skill and practical ability, a considerable number of experiments are only confined to theoretic verification.

(3) Segmentation. The theoretical teaching and practice teaching in universities are disjointed; practice teaching itself is also divided seriously. Carry out practice teaching on the single course and single skill. Practice teaching is lack of scientific, systematic and comprehensive. The practice teaching management department is separately, lacking of communication and coordination mechanism.

Misunderstanding leads to work deviation, which serious impact on training practical ability and innovative spirit of college students, and become an important crux of affecting the quality of personnel training. In fact, practice teaching and theory teaching are not only the two sides and two cycles in same teaching activities, interdependence and mutual support, but also it relied on practical knowledge or the practice ability has an important position[4]. Practice teaching is an important means to train and bring up creative talents. Therefore, in the practice teaching system, practice teaching link not only set the basic experiment, but also professional experiment. Not only pay attention to the basic skill training, but also the innovation ability training. Not only emphasis on the overall training of students' professional operating skills, but also the cultivation of students' basic qualities. Practice teaching is a teaching method of college talents training, which is scientific and systematic. Firstly, practice teaching and theory teaching should form an organic system. The two elements should mutual cooperation and promotion. Secondly, practice teaching curriculum system setting should around practice teaching goal to design each links in practice, link to link, linked closely. Finally, the practice teaching management departments should work together with division of labor, overall operation from top level design, maximizes the overall function of the practice teaching system, to improve students' practical ability.

\section{Construction of multi-mode practice teaching system}

The diversity social demand for mechatronic talents determines the diversity university talent training. The construction of practice teaching system should provide the development space for the talents cultivation and improve the students' comprehensive qualities. In order to meet the requirements of talent training, the multi-mode practice teaching system is proposed. As shown in Fig.1, the multi-mode practice teaching system includes three modules: Basic training, Quality development and Innovative development.

The basic training module including curriculum experiment, curriculum design, professional training, production practice and graduation design, etc. Each link is connected with others and throughout the practice teaching process. Basic training module is mainly to cultivate students' manipulative ability, verify the theoretical teaching content, and deepen the understanding of theoretical knowledge. It is the basic link of talent training and compulsory part of all students.

The quality development module is mainly to develop the professional quality of students by the way of discipline competition. The discipline competition is set up in three directions: software design, electromechanical control system design and mechanical structure design. Software design includes 3D modeling competition and NC machining simulation competition. Electromechanical control system design includes Fischer design competition and Robot competition. Mechanical structure design includes Mechanical innovation design competition, etc. The quality development module is to cultivate students' professional application ability, solve practical engineering problems with the professional knowledge, and achieve the purpose of improving the professional quality of students. Innovative development module is mainly to cultivate students' innovation and creativity ability by the way of provide scientific research platform, such as scientific research project of college students and 
Research assistant posts. The main purpose is to cultivate students' ability to analyze and solve problems, formation of creative ability and innovative thinking.

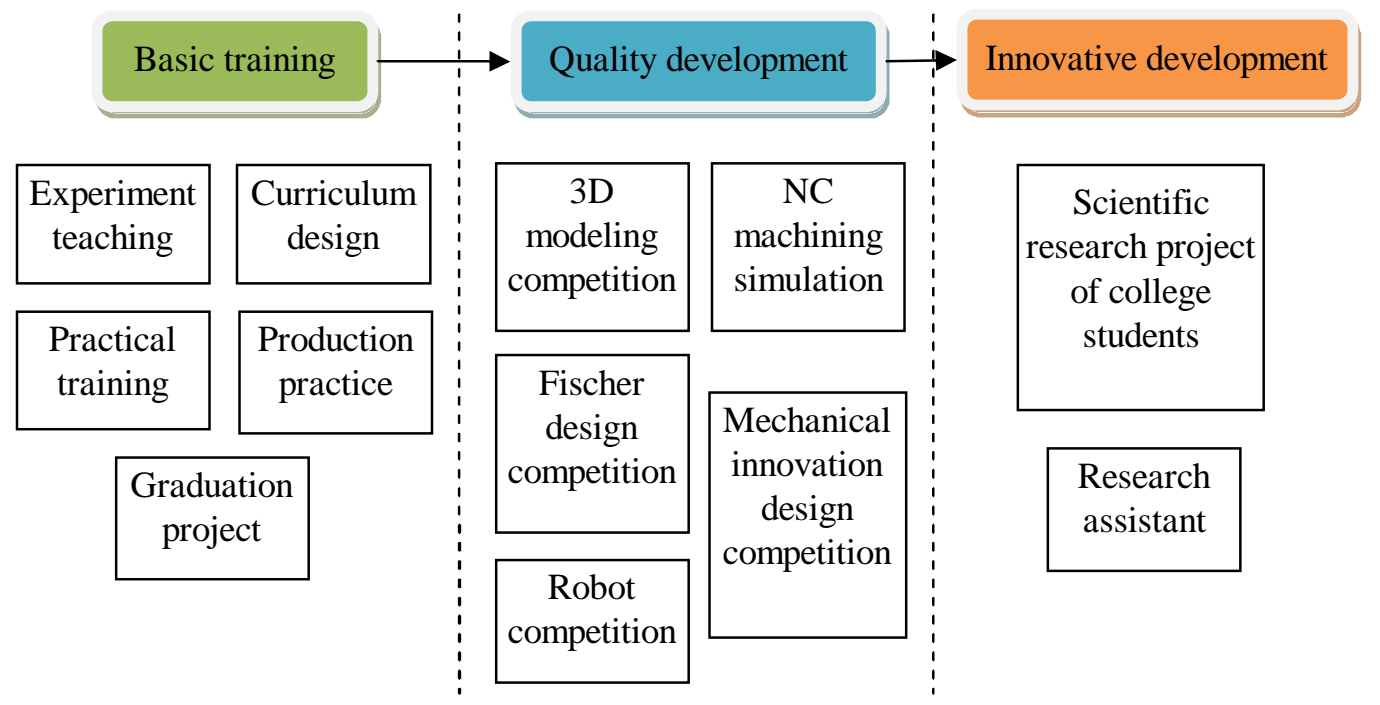

Fig.1 Multi-mode practice teaching system

Not all students are able to participate in the training of the whole process of the three modules. Universities should be personalized training based on itself resources configuration and students' ability and interest.

\section{Practice teaching quality control system}

Practice teaching quality is the life of practice teaching and the key element to measure the success of talent training. The talent training under the multi-mode practice teaching system must have scientific and systematic quality control system. As shown in Fig.2, the practice teaching quality control system is composed of three parts: management system, executive system and feedback system.

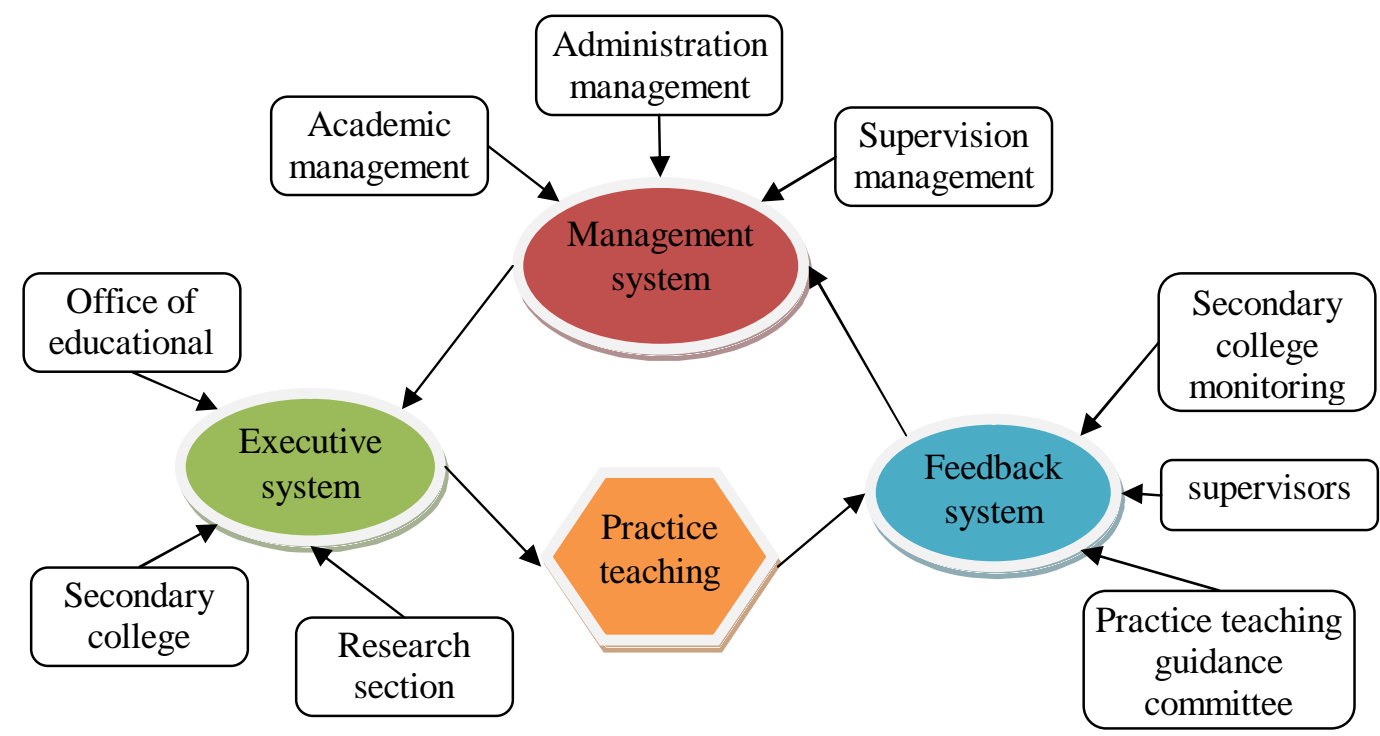

Fig.2 Practice teaching quality control system

The management system is the top-level design which is responsible for the project setting, resource allocation and achievement evaluation of practice teaching. It mainly consists of three parts: administration management system, academic management system and supervision management system. The administration management system is the command center of the management system. Its major function is to plan, organize, coordinate and monitor the practice teaching activities, ensure the realization of the teaching practice goal. The academic management system is mainly to put forward 
practice teaching idea and teaching principle, determine the practice teaching general goal, validation practice teaching rules, regulations, practice teaching plan, outline and instruction book, etc. The supervision management system is mainly to develop practice teaching supervision methods, supervise the practice of teaching activities, check the status of practice teaching activities, direct practice teaching, conduct special inspection, collection and practice teaching information feedback and so on. Execution system is the stage of implementation. It is divided into three executive agencies: office of educational, secondary college and research section. The office of educational is responsible for practice teaching task assignment, practice fund management and student score management. The secondary college is responsible for teaching site, equipment and consumables management. The research section is responsible for practice teaching arrangement and implementation of specific teaching process monitoring.

The feedback system is mainly to induction and consolidation the feedback information from different channels timely and accurately, and provides feedback information to the practice teaching quality monitoring system at the same time. So, the management system can control, modify and improve practice teaching activities and improve the quality of practice teaching.

In the practice teaching quality control system, management system is the guarantee, executive system is the core and feedback system is the foundation. The three subsystems are interdependent and mutual coordination to form the overall function of the practice teaching quality control system.

\section{Conclusions}

Practice teaching is an important part of creative education and creative talents training. The scientific and systematic practice teaching system is the key element to ensure the talent training. The multi-mode practice teaching system and its quality control system are constructed for the high quality and innovative talents training. It is of great significance to improve the quality of talent training.

\section{References}

[1] P Haihan, T Zhi: Redesign to University Practice teaching System. China higher education research,Vol.2(2012),p.104-106

[2] Z Shu:The Industry 4.0 and Intelligent Manufacturing. Machine Design and Manufacturing Engineering., Vol.43(2014),p.1-5

[3] X Huajun, L Qian: Analysis on the current situation of practice teaching in Chinese Universities.University(Academic), Vol.5(2012),p.44-49

[4] Z Xiaobin: Discussion on Practice teaching System for Cultivating Undergraduates Majoring in Economics and Management. Research and Exploration in Laboratory,Vol.26(2007),p.1-4 